ARTICLE

https://doi.org/10.1057/s41599-020-0477-5 \\ OPEN
}

\section{The gains of reduction in translational processes: illness blogs and clinical-ethics cases}

\author{
Anita Wohlmann (10 ${ }^{1 \times} \&$ Susanne Michl (10 ${ }^{2}$
}

\begin{abstract}
Translational processes in clinical contexts and literature studies are ubiquitous. This article first outlines three different models of translation, which describe how source text and target text relate to one another, namely as sameness, reduction, and production. The article makes a case for understanding translation as a relational ontology and focuses on the role of reduction in translational processes. Rather than condemning reduction a priori for its many problems, the authors suggest reevaluating reduction as a necessary and welcome dynamic and dialogical process. Reduction is approached from a double perspective: In literary studies, reduction is a process that entails condensation, rawness and directness, and thus reduction is associated with a positive ethos. In science studies and comparative studies, reduction has been described as a heuristic mechanism that enables theory building. The article makes a contribution to translation in clinical contexts by describing the gains of reduction in translational processes. These claims are exemplified through the analysis of two text genres: an illness blog and clinical-ethics cases. Our analysis suggests that reduction is not necessarily an antonym to production or complexity but a practice that makes visible the ties that motivate translation or are its result. In doing so, the contribution aims to provide a more positive account of the processes of reduction in translational practices.
\end{abstract}

\footnotetext{
${ }^{1}$ Department for the Study of Culture, University of Southern Denmark, Odense, Denmark. ${ }^{2}$ Institute for the History of Medicine and Ethics in Medicine, Charité University Medical Center, Berlin, Germany. ${ }^{凶}$ email: wohlmann@sdu.dk
} 


\section{Introduction: three approaches to translation}

ranslation in clinical contexts and literature studies has been conceptualized in diverse ways. A naive model sees translation as an act of transparent copying or duplicating, in which the original (con)text is (almost) identical with the target or should strive for as much equivalence as possible (e.g., Baker, 2001, pp. 122-123). In other words, this model of translation hopes to produce a presumably ideal mirror in which original and target are the same. Unsurprisingly, this model has garnered critique and seems outdated. For example, Engebretsen et al. (2017) argue that Knowledge Translation (KT) presupposes a perfect translation of knowledge or research results that is characterized by neutrality, transparency and "fidelity to the source." In this conceptualization, "translation-if it is to be felicitous-is non-productive. Its principal purpose is to preserve and implement the original, scientific content in new sociocultural contexts" (Engebretsen et al., 2017). To understand translation as an attempt to create a relation of sameness between original and target implies that the translator immerses herself in the original text and creates "a literary symbiosis" with the author and thus becomes invisible herself (Vergnaud, 2018). Such "a mystical mirroring process" suggests a utopian or "Romantic obsession with originality" (Damrosch, 2003, pp. 156, 167). A translation thus neither changes the original nor the target.

A second model assumes that the target of a translation is a reduced version of the original. A clinical trial translates a medical problem into the artificial, clean, and reduced setting of the laboratory and an experimental design, which is stripped of the messiness of social-cultural contexts, subjective experiences and other interfering variables (Cartwright, 2007, 2011; Pearce et al., 2015). Thus, the target is a condensed, incomplete version of a complex original and only selected variables of the original are retained. Subsequently, the results of the trial are applied to patients and have to prove themselves in specific sociocultural contexts. Unlike the group of early trial participants who have been selected by more or less artificial inclusion and exclusion criteria, the presumably "pure" research results are now brought in contact with a complex and unpredictable context. A similarly suspicious disposition is discernible in the critique of the metrics and tools of evidence-based approaches, which are considered to problematically reduce the complexity of the "real world" to yesand-no answers and measurable variables. Analogously to the model of translation as sameness, one might say that this negative model defines translation as reduction, and thus the target is considered minor or lacking in comparison to the original.

In literature studies, the history of translation, as literary scholar Rita Felski argues, is characterized by a similar skepticism, which she describes as an "ethos of negativity" and suspicion (Felski, 2016, p. 747). Translation, according to this negative view, distorts, takes away, reduces, compromises and falsifies an allegedly pure original. As Felski maintains, "To its critics ... translation is at best a necessary evil and at worst a form of deeply troubling cooption-one that levels cultural differences and mutes linguistic otherness while encouraging a linguistic sampling and nonchalant appropriation of other literary and cultural worlds" (Felski, 2016, p. 750). Translation is thus complicit in processes of "exclusion and hierarchies of power", as well as "social homogenization" and "a more general flattening out of cultural and linguistic differences" (Felski, 2016, p. 751). In these conceptualizations, translation is a linear and hierarchical movement from source to target, in which the original source is considered of higher value while the target is treated as secondary and lacking.

As a response to the models of translation-as-sameness or translation-as-reduction, a third model has been suggested, in which translation is an act of co-creation and meaning production. As literary scholar Mita Banerjee argues in relation to the translation of disability experiences, "much more is found in translation than gets lost" (Banerjee, 2019, p. 13). David Damrosch makes a case for how linguistic translation can be an opportunity because translation can increase transnational exposure, legibility and influence across different cultural audiences and historical times (Damrosch, 2003, pp. 170, 289). Such positive effects may even occur if the traveling of a text via translation involves misunderstandings, misconceptions, and refractions (Lefevere qtd. in Felski, 2016, p. 753). Similarly, Paul Ricoeur recasts translation in more positive terms, considering it not only a challenge but also a "source of happiness" (Ricoeur, 2006 , p. 3). Ricoeur suggests considering translation with dispositions of hospitality, generosity and openness: "The happiness associated with translating is a gain when, tied to the loss of the linguistic absolute, it acknowledges the difference between adequacy and equivalence, equivalence without adequacy. (...) Linguistic hospitality, then, where the pleasure of dwelling in the other' language is balanced by the pleasure of receiving the foreign word at home, in one's own welcoming house" (p. 10). Similarly, in the case of knowledge translation from clinical trials to the bedside, something is invariably added or supplemented. For example, a target culture always contributes to scientific evidence (Engebretsen et al., 2017). Drawing on Derrida, Engebretsen et al. suggest that "translation does not only duplicate the original message, it also completes the original message ('the supplement supplements') by fulfilling one of its possible interpretations" (2017). For this reason, shifts of meaning need to be acknowledged and defined as "a creative potential rather than as a barrier" (Engebretsen et al., 2017). In other words, this model sees translation as production. The target thus contains "more" than the original.

Such positive conceptualizations of translation resonate to some degree with approaches that understand translational processes as a matter of relations and connectivity. We follow Rita Felski when she suggests considering translation a relational ontology. This broader conceptualization of translation allows us to understand the translational process "not as an oscillation between oppressive sameness and radical singularity, but as chains of association and mediation that have no predetermined politics, but must be described in as much detail as possible" (Felski, 2016, pp. 750, 754). Felski's approach resonates with the three models of translation we outline above because translation, for her, is not primarily about assessing what is added, left out or considered identical but about "the nature of these ties" themselves (Felski, 2016, p. 761). To understand a translational practice through its ties and relationships-rather than comparisonacknowledges that the world and its objects are "always already entangled, mediated, interdependent, intertwined" (Felski, pp. 753-4). As a consequence, we can redirect our attention-from concerns of adequacy and equivalence between origin and target-to the nature of the ties, how they are made and which actors are involved as entangled co-constructors of knowledge (p. 761). Rather than critiquing translation or bemoaning its betrayal, lack of purity and transformation, we can gauge, as Felski argues, "the uses and merits of specific translations-which involve losses and gains and misunderstandings, but also the possibility of new affinities and attunements" (p. 752). As a literary scholar, Felski applies this rationale to literary works; yet one of the examples she quotes illustrate the productivity of her conceptualization of translation to the medical context: The ethnographic research by Annemarie Mol in The Body Multiple: Ontology in Medical Practice (2002) suggests that it is via translation that symptoms, objects, actions, and interpretations are connected and coordinated (Felski, p. 752). "It is 
translation ... that allows the symptoms described by a patient, the blood vessels viewed under the pathologist's microscope, and the images produced in the radiology lab to be brought together under the shared term 'atherosclerosis"' (p. 752). Translation thus ties different actors together and this process enables new insights.

For example, a focus on the new insights emerging from translation puts a more positive spin to the equivalence concept of translation. Rather than dismissing this notion as naive, we may consider the gains of full equation and transparent translatability, and we may ask which legitimate desires and motivations it expresses. After all, is it not an understandable desireboth by clinicians and patients-to achieve a perfect translation, in which the effectiveness of a drug under laboratory conditions is identical in a real-life context? We may dismiss this desire as utopian, romantic or naive, and yet it is a reasonable intention and latent desire that drives clinical research and trials. A focus on the nature of the ties and thus the motivations, intentions and aspirations that connect original and target in clinical contexts entails a different ethos or attitude towards these ties. Thus, rather than suspecting them to be distorting, falsifying influences that need to be overcome, we may also take such desires and intentions at face value and acknowledge them as sincere and appropriate aspirations. The relation between original and target may then be better described as a prescriptive statement: the original shall be equal to the target. Alternatively, we can describe the relation as the desire for the best possible approximation, simultaneously acknowledging the possibility that a concurrence or sameness may never be fully achieved.

Such a positive ethos also invites a reevaluation of the notion of reduction in translational processes. As we outlined above, reduction has been viewed in an overly negative way. From a literary perspective, however, reduction is not necessarily about loss and distortion. In fact, reduction as a form of condensation is a writerly practice to get closer to a poetic "truth." In this sense, reduction does not stand in an antonymic relation to production or gain. It is not a "less" as opposed to a "more." Instead, reduction can be cast as a sobering crystallization and an approximation. In the medical context, too, reduction carries latent potentialities. Reduction is necessary to create better translations because it enables comparability and the production of case series. In this sense, reduction is a welcome and necessary process in producing conclusive data.

In this paper, we hope to add to the discussion of translation in clinical contexts by reconsidering the role of reduction. A focus on the gains of reduction generates, we suggest, a more capacious understanding of translation. Drawing on Felski, we understand translation as a relational ontology and focus on the ties that translations establish. In our understanding, translation encompasses, on the one hand, translations between different languages, for example, between German and English, as practiced by ourselves in the examples we present below, and between professional jargons and ordinary speech as exercised by the authors we consider. On the other hand, our understanding of translation also includes, more generally, the transition of meaning from one context to another, which our texts exemplify as well. Translational processes, we argue, are relational dynamics and involve interpretations, negotiations and appropriations. In advocating a positive stance towards reduction, we do not wish to challenge or reject the critical voices we mentioned above. To be clear, we do agree that the skepticism towards translation-as-sameness is justified and that it is quite true that translation is, indeed, productive. However, in challenging the antonymic relationship of reduction and production, we question the negative ethos towards reduction. Our aim, however, is less evaluative as it may sound. Rather than praising reduction over production, we try to trace the ties that translations enable, and we focus particularly on reduction as one tie or connection between source and target. In doing so, we explore how reduction may usefully inform translational processes.

In bringing together concepts and concerns from clinical contexts and literary theory and in demonstrating how they inform one another on a theoretical level, we also propose that this approach has a practical value. In our analysis, we turn to two examples that destabilize disciplinary boundaries by the way that they translate medical knowledge: illness blogs and case histories. More specifically, we analyze a German illness blog by Wolfgang Herrndorf and a number of clinical-ethics cases in the German ethics journal Ethik in der Medizin. The two genres (however different the contexts from which they originate may be) share similarities in the production of medical knowledge via processes of reduction. The following questions inform our analysis: how can we understand translation as a form of reduction without necessarily casting reduction as loss or lack? What does it imply if one approaches translational processes through the lens of reduction? What does reduction mean in such different contexts as literature on the one hand and the life sciences, or the clinic on the other? Are these approaches (as well as the desires and intentions by which they are informed) even comparable?

\section{On reduction}

In the context of medicine and even more broadly in the life sciences, it is controversially discussed to what extent the overwhelming use of "reductive" methods leads to new insights and whether or not such methods are essentially limiting. Several publications from the life sciences have called for moving "beyond" or away from reductionism in the investigation of complex systems (see for example Levenstein, 2009 or Ahn et al., 2006). A vivid and still ongoing debate in the field of philosophy of science has contributed to a conceptually differentiated view on reduction and reductionism (Kaiser, 2015, 2011; Nagel, 1961). In our contribution, we refrain, however, from the question, whether or not reduction is appropriate and lives up to its promises for a better understanding of complex systems. Instead, we are inspired by Niklas Luhmann's conceptual tools and notions in system theory: reduction in a broader clinical setting may be understood as the essential communicative means of a system to deal with a complex environment (Luhmann, 1987). One of our examples, the reasoning in cases, illustrates such a reductionist mechanism in the negotiation with complex situations: in clinical cases, all irrelevant information is stripped off in order to make particular situations comparable to each other and to come up with wellconsidered decisions and courses of actions. A similar intentional gesture can be found in text-based datasets or series, in which data figures as a particularly reduced form (not in quantity but in quality) that ensures comparability when assembled in datasets. Such comparability is possible because data is a quasi-de-contextualized, extracted part of a complex whole. This is the case for clinical cases, although the great difficulty here lies in maintaining the complexity and heterogeneity of the individual cases while at the same time ensuring their comparability for different users. Thus, from the perspective of science studies, reduction is a prerequisite for comparative practices, and the example of clinical case series suggests that reduction may actually generate new knowledge and insight while it balances context sensitivity and practical reasoning. Similarly, in comparative studies, reduction, as for example in the reductive assumptions and evaluations that categorizations and stereotypes make, has been discussed from new angles. Following Susan Stanford Friedman (2011), reductive comparisons problematically decontextualize, but it is also important to acknowledge that not all reductive comparisons are 
necessarily problematic. In reducing the particular, the individual and idiosyncratic of a given situation or object of comparison, the person who compares can, as Friedman argues, achieve new insights and generate new theories (p. 756).

In literary studies, symbols, metaphors, poems, and short stories are considered the products of reduction, condensation and conciseness. They are defined as rich and thick containers of knowledge and experience. While the research objects of literary studies are often praised for their indirectness, figurativeness and ambiguity, this need not be the case. For example, in Imagist poetry, Ezra Pound, William Carlos Williams, and others have foregrounded direct, literal language and common speech. Imagist poetry "presents an 'image' (vivid sensory description) that is hard, clear, and concentrated" (Abrams and Harpham, 2012). Similarly, the short prose of a writer like Ernest Hemingway is the result of meticulous processes of omission, which result in a condensation of experience and a compressed, concise material. As Hemingway maintained in his famous explication of the "iceberg theory":

If a writer of prose knows enough about what he is writing about he may omit things that he knows and the reader, if the writer is writing truly enough, will have a feeling of those things as strongly as though the writer had stated them. The dignity of movement of an iceberg is due to only one-eighth of it being above water. (Hemingway, 1999 pp. 153-154)

A similar argument for the value of reduction is made by contemporary poet Mark Doty, who, in a conversation on the role of poetry in medical training, maintains that "The poem is a place where we think about interiority and where we find a reflective individual experience crystallized or given to us in a pure and distilled form" (Campo and Doty, 2018). Poems and short stories are thus translations of thick experiences and sensory perceptions. They are the result of processes of reduction and yet they can reproduce the "original" esthetic sense of rawness or purity. From this perspective, reduction is a process that enables rather than constrains. Reduction can entail a thickness of interpretations and meanings. From the perspective of poetry and short fiction, reduction is thus a positive process of transformation from one area or domain to another, and it helps us describe what translation may enable and which ties it generates.

\section{Tracing reduction in illness blogs and case studies}

To illustrate the gains of reduction in translational processes, we discuss two genres. We understand a genre as dynamic text productions or writing practices, in which disciplinary conventions and readers' expectations continuously shape and coconstruct the genre. Genres thus represent fluid and relational cultural practices and not "deep repositories of hidden meanings, formal structures, or subtextual insights" (Mittell, 2004, p. 27; Oró-Piqueras and Wohlmann, 2015). Our genres, illness blogs and case histories, do not seem to have much in common at first sight; and yet, when understood as writing practices, they draw on similar techniques and strategies.

In illness blogs, patients record their (or their relatives') experiences on a daily or regular basis. In doing so, such illness blogs create a series of personal experiences that are electronically recorded and published (Sorapure, 2003). Accordingly, blogs are a platform on which, similar to diaries and journals, the sequential, day-to-day evolvement of an illness rather than the coherent, reconstructed and polished prose of a conventional illness narrative (in book form, for example), can give expression to the fractured and changeable nature of the disease and clinical pathways. In contrast to published diaries or illness narratives, illness blogs are perpetually revisable (Sorapure, 2003). Moreover, given that blogs are published in an online context, they do not only bear some similarities with the data esthetic of electronic patient records, they are also dialogic and interactive, inviting other readers to comment and relate with the blogger (Kitzmann, 2003).

Similar to blog entries, case studies present personal experiences. They deemphasize the temporal, sequential structure and present condensed, coherent and sound narratives that point beyond the particular case to an abstract general (either an abstract rule, principle or notion) (Süßmann et al., 2007). Sometimes, they even have a pedagogical role when they serve as prototypical cases which can be used to shed light on other patient stories and the best way to proceed. In several disciplines such as ethics (Jonsen and Toulmin, 1989), psychoanalysis (Forrester, 1996), law (Kudlich, 2007) and medicine (Hunter, 1991; Hess, 2007; Behrens and Zelle, 2012), case studies are considered a specific form of knowledge or a way of reasoning (Forrester, 1996). These perspectives do not detract from the character of case studies as, first and foremost, narratives and stories (Düwell and Pethes, 2014). Finally, like illness blogs, case studies are particularly productive in their dialogical form. They do not only refer to other texts, they also address an open question and pass on this question-sometimes more, sometimes less explicitlyto the reader or commentator. As early as 1930, the literary scholar André Jolle emphasized in his book "Simple Forms", that the case is a peculiar form which imposes the duty on the reader to give an answer or make a decision (Jolle, 1968, p. 191). The interactive nature of case series thus echoes the function of blogs.

\section{Illness blog: Wolfgang Herrndorf}

The German writer Wolfgang Herrndorf began writing his blog Work and Structure (in German: Arbeit und Struktur) in March 2010. A month earlier, he had received the diagnosis of a glioblastoma. His life expectancy became a continuous point of negotiation over the next months and years. The blog was a digital diary that was meant, initially, as a way to connect him with his friends and share news about his current condition (443). Half a year later, the blog was opened to the public and was read by an increasing number of readers. A post on August 2013, marks the end of Herrndorf s blog and life: He committed suicide.

When Herrndorf received the devastating diagnosis, he had been a renown and passionate writer of novels. After the diagnosis, he was tormented by many questions. How should he use the remaining time of his life? How should he fill the many hours of treatment, waiting, anxiety and recovering? In April 2010, his answer was: "I feel best when I work." In the years between 2010 and 2013, Herrndorf finished two novels (Tschick, Sand) and wrote regularly in his blog. Work and Structure steadied him in these unsteady times.

The translational work in this blog occurs in several directions and on multiple levels:

- between Herrndorf and his readers, to whom Herrndorf translates the news of his life and his state of mind

- between Herrndorf and his doctors, from whom he receives at times contradictory recommendations for treatments

- between Herrndorf and the numbers and statistics in medical studies, which he researches himself and tries to integrate into his life (and way of thinking)

- between Herrndorf the patient and Herrndorf the writer, who both try to understand the massive changes that the diagnosis has on his life and identity

The blog chronicles the many doctor visits and treatments Herrndorf underwent. Herrndorf also relays his own research in the form of quotes statistics on survival rates and studies on the efficacy of new treatment options, and reports on blood tests, magnetic resonance imaging (MRI)-scans, the side effects of 
chemotherapy, radiation and drugs. He even copy-and-pastes a graphic representation of the survival rates of patients who were treated with temozolomide (TMZ) plus radiotherapy according to MGMT promoter status (on 29 March, 2010, 12:30). Each blog entry is framed by digital information on the exact time and date of the blog entry. The entries thus resemble a medical record or medical chart, in which Herrndorf lists, sometimes meticulously, the side effects of his treatment, the frequency of chemotherapy or radiation he receives. In a sense, the blog entries are the condensed raw material of Herrndorf s journey as a patient.

An esthetic of reduction informs Herrndorfs style of writing. Similar to a logbook, the entries are short, sometimes only a sentence long, and sometimes they resemble quick notes rather than full sentences. Contrary to the scope of illness narrative which often contain life reviews, detailed descriptions of thought processes and rich contextual information, Herrndorf's blog is a compressed version of an illness narrative. The tone is neutral, matter-of-fact and distant. For example, on 27 March, 2010, at $18: 49$, Herrndorf begins his blog entry in the following way:

"Googling again: A hypericin study on mice with good results. A chloroquine study in humans from the National Institute of Neurology and Neurosurgery of Mexico, 2005: The chloroquine group survives 24 months on average, the placebo 11 months. Thirty participants, and somewhat confusing: the randomized chloroquine group is on average five years younger, with the same Karnofsky. In my mind, this does not seem to be completely irrelevant. Follow-up studies?" (this and the following are our translations)

The entry reports, objectively, on the results of his research, and Herrndorf's role is that of the observer and minute taker. Herrndorf seems to copy or imitate the tone of the reports into his own writing and thinking. The target text is thus characterized by efficiency and austerity, a focus on facts and a minimalist, laconic and even blunt esthetic. In a sense, in immersing himself in the objective and distant style of the clinical information, Herrndorf approximates the source domain of clinical statistics and his own target context, his illness experience. In both source and target, affective responses and the subjectivity of the speaker/ writer are reduced and almost erased. The blog is, in many ways, a dataset, but it is also a narrative, a story of Herrndorf s lived experience. Thus, the blog genre that Herrndorf chose and the particular style of his entries destabilize a rigorous distinction between original, clinical information, and target context.

Repeatedly, the blog breaks out of its stance of objectivity and laconic neutrality. In these moments, the factual tone is disrupted by a flash of anger, a poetic phrase or a funny anecdote. For example, on 29 March, 2010 (at 12:30), when Herrndorf received the news that a genetic test was positive, a tirade of swear words unfolds, which covers several lines and are inventive, deeply moving, and even comic.

"Appointment with Prof. Moskopp and a hit in the genetic lottery: I have the shitty methyl group. I am hypermethylated. The crucial marker of whether the body is likely to respond to Temodal at all. And now fuck you in your small, godless, unhypermethylated ass, you dirty little cancer. The probability was $45 \%$. The result is a few weeks or months. Statistically. But statistically, it is also like this: After two years, the curve becomes flat." (29.3.2010 12:30)

Because such statements occur against the background of an otherwise toned-down and seemingly cool report, their effect is even more powerful. Moreover, the synchronicity of the blog and thus its status of having been a live-report between 2010 and 2013 implies a potential open-endedness but also the possibility of a discontinuation of the writing and thus a sudden ending of the blog.
The blog entries are fragments, and it is only later, when the blog was edited and published in book form, that it appears like a coherent story, an illness narrative or autothanatography (Smith and Watson, 2001). The blog form, however, makes possible another type of storytelling: as a collector and translator of the personal bits and pieces of his experience, Herrndorf can, at any time, stop the process of publishing this information. The blog is thus characterized by an unstable, unpredictable and incorporeal quality. As a record of illness, the blog enables him to capture the fragility and incoherence of his illness experience. In this sense, it is very different from the tactile book form, which has a material reality and in which the raw data appears as a coherent, polished story - with a clear beginning and ending, a preface and an afterword (Höttges, 2009).

Translations between clinical data and Herrndorf s lived experience also occur on the level of figurative speech. Again, they are informed by an esthetics of reduction. Several times, Herrndorf refers to "Karnofsky"- the Karnofsky Performance Score, which he does not care to explain. The score allows clinicians to quantify and evaluate a patient's health status and make predictions for the patient's ability to survive chemotherapy. Karnofsky is basically a number on a scale of 0 (signifying death) and 100 (signifying perfect health). In Herrndorf s blog, Karnofsky is a number, too, and it is a character in the story of his life. Karnofsky is personified and described as an old friend and companion with whom Herrndorf hangs out on a sunny day at the Spree (22 March, 2010). On 24 March, 2010, Karnofsky is a travel companion:

"According to the Apogenix website, less than 30\% of glioblastomas survive the first year. So far, it has always been seventy. Thirty, seventy, whatever: Old Karnofsky and I are going by taxi anyway."

One might argue that Herrndorf reduces an otherwise complex method of measuring a patient's health status to an imagined persona or character. One might also argue that the personification adds a sense of humor and playfulness. In this sense, the personification unsettles the validity, appropriateness and usefulness of numeric scales in the lived reality of an illness. The boundaries between what is medically significant and personally relevant are unhinged. At the same time, the personification reminds us of the literal reference of the term: the oncologist David A. Karnofsky, after all, was a real person. By removing the implied meaning (and thus the validity of the numbers to predict life expectancy) so that the actual person behind the complicated score comes into focus, Herrndorf approximates source and target and focuses on the condensed, raw meaning(s) of the Karnofsky scale: Karnofsky is a figure-numeric and, literally, as a person-and it is in this double function that Karnofsky will accompany him. The practice of personification thus allows Herrndorf to create a different kind of tie from a reductive name and number.

To sum up, Herrndorfs blog project does a type of translational work between clinical sources and a patient's lived experience and, in doing so, it destabilizes the binary construction of these allegedly polar opposites. The translational work creates and strengthens ties, connections and relations. In the case of Herrndorf's blog, these ties materialize on the level of style, tone and esthetic choices. The blog's frequently neutral, observational tone and its matter-of-factness in reporting on events creates a relation of hospitality between clinical data and personal story. To echo Paul Ricoeur's concept of linguistic hospitality, the clinical information on statistics and treatment options is invited into the "house" of the novelist and writer by way of googling, incorporating charts, echoing the studies' tone and personifying the data on life quality and survival. As a consequence, the novelist himself starts to feel at home in the house of raw data: in his blog entry of 24 March, 2010, Herrndorf notices a fluency in medical 
lingo that emerged from the translational process. He seems almost amused when he maintains that he has learned to say complicated terms as easily and naturally as compounds in idiomatic speech, such as "butterflies in the belly" (in German: Schmetterlinge im Bauch). Herrndorf even maintains that he knows to some extent what the complicated and strange medical terms mean. The medical words and statistics are thus no longer strange and alien; the translation process has resulted in a familiarization and approximation. Thus, Herrndorf, as a guest in the "house of medical data," has immersed himself in the form and tone of the original (con)text. The allegedly raw, pure data as well as the subjective and highly personal experiences of the target context sit at a table of mutual hospitality.

\section{Case series in a clinical-ethics journal}

Case studies are at the heart of the sub-discipline clinical ethics and are called a "key genre" and the "data of bioethics," as Tod Chambers maintains (Chambers, 1999). They are the privileged format in which moral deliberation meets a specific context and in which suffering is an embodied reality and concerns an individual patient. Journals devoted to clinical ethics regularly publish ethical case narratives in special forums, which highlight the serial character of the genre. They are used (1) as a means of testing and illustrating abstract moral theories against the backdrop of reallife; (2) as a means of communicating by citing commonly shared narratives; and most prominently (3) as a means of building up a casuistic, a series of cases. In doing so, cases weigh the moral impact of each story and meticulously identify similarities and differences between the cases in order to justify a particular course of action in individual situations.

The translational work in case studies occurs in several directions and on multiple levels:

- between the narrator of the case who raises the ethical question and the commentator, respectively the reader, who is urged to answer the question

- between the case as the individual illness story of a patient and the case as part of a series of cases

- between the narrator of this special form of ethical cases (dealing with illness as a boundary experience for the patient) and readers familiar with the more traditional form of clinical cases (dealing with illness as a clinical entity)

- between the presentation of the case in its diachronic perspective (the life of the patient, his or her lived experience and his or her evolving attitude towards illness, life and death over the course of a lifetime) and the presentation of the case in its episodic perspective (the decision about further treatment as an event within this life span)

The following analysis of ethical cases is based on the German journal Ethik in der Medizin (English: Ethics in Medicine), which published a series of ethical cases between 1998 and 2017. The publishers of the journal regularly call on clinical-ethics consultants or other professional groups to write down their experiences with difficult and complex cases and to put them up for discussion and comment. The cases are thus not prototypical cases of pure invention but draw directly on the experiences of ethics consultants in various German hospitals. Quite similarly to illness narratives, cases are written by health care professionals against the backdrop of exceptionally thick experiences. One might wonder why, generally speaking, the case presentations in the journal are so short: the cases often consist of only a few paragraphs which fit on one page. This is remarkable given that clinical ethicists with a more phenomenological approach, such as Richard M. Zaner, have published more comprehensive ethical case narratives and have garnered much professional acclaim
(Zaner, 2004, 1993, see also Ford and Dudzinski, 2008). One might even argue that the presentation of moral problems requires a thick and detailed description of the course of event, the time and space when the events happened and the people who were involved. However, even a more detailed and multi-layered description would have to carefully select the most important aspects that are both morally relevant for the decision to make and suitable for comparison with other cases.

However, instead of blaming the authors for not doing justice to complex situations, it is worthwhile to draw attention to the type of translational work that is obviously at the heart of this kind of writing practice. Cases are stripped off additional information so that the variables and parameters of the case become comparable to other cases in a larger casuistry. It is this process that enables health care professionals to discuss the moral reasoning and the implicit principles behind decision-making processes. In this sense, each case is part of a larger dataset and the many reductions that are at work are the condition for its existence as a case. Reduction, therefore, is a crucial component in theory building and the acquisition of knowledge. Therefore, in the following analysis, we will read clinical-ethics cases as thin descriptions of thick experiences and focus on what is gained through reduction.

A systematic review of the 55 case narratives published between 1998 and 2017 in Ethik in der Medizin reveals four predominant narratological reductions: (1) the absence of the first-person-narrator, albeit the cases are obviously recordings of first-hand experiences and the reporting ethics consultants is him- or herself involved as an actor in the plot; (2) the presentation of thin or stock characters, who are often only characterized by a few remarks or quotations; (3) the use of a detached, objective, distant style; and (4) an omission of particularity in the information on time and space (see also Chambers, 1999). By presenting the case with no visible narrator, no psychologically complex characters and quasi no indication for a specific context, these absences, gaps and stylistic choices are, in fact, rich repositories of meaning: in its reduced form, each case generates (to the trained reader) ties of recognizability and familiarity with the form of medical casuistry in general and with approximatively similar cases in particular. The sparse and reduced information will ignite immediate cognitive responses in the trained reader, who is the intended audience of this case, and will invite her to make immediate assumptions about potential diagnoses and further actions to determine the course of treatment. What is gained via translation and reduction is thus a sense of community among interested medical professionals, who share similar experiences, and that gradually brings into shape and visualizes a complex and ambiguous case.

However, the narrators of the cases walk a fine line. The more singular the story, the less it resonates with the readers' similar or comparable experiences. The writing practice consists in focusing on recognizable character types or typologies of ethical dilemma situations without reducing the complexity of the individually experienced stories. This explains why narrative stylistic devices are used frequently, and we will examine three aspects heredirect reported speech, symbols, and aphorisms-as they particularly pertain to our focus on reduction.

Directed reported speech enables the authors of the case to convey a sense of authenticity and to present the complexity of the situation. In doing so, the authors can strengthen the ties of trust and community with their readers. In transferring the patient's direct speech, the case description suggests a "fuller picture" of what happened and gives a voice to the patient, and yet in their extreme shortness, the patient's apprehensions and attitudes are reduced to soundbites that generate a "feeling" for the situation. As Tod Chambers points out, fragments of reported speech often signal a moment of high drama and crisis. However, 
the analysis of the case series shows that one might also read them as characterizations of the patient. By extension, this characterization reinforces the recognizability of a certain type of patient among readers. The reported speech signals a particular patient attitude, such as resistance, a fatalistic acceptance, resignation or readiness for fighting against the illness. In some ways, these short bits of information invite psychological classifications and risk overlapping with cultural stereotypes and clichés.

Figurative speech, as for example in the use of symbols, represents another dimension that informs the translation between the lived experience and the narrative case form. The carefully selected bits of reported speech often contain symbolic images, which are condensed forms that suggest rich meanings and insight into the case. In one of the cases in Ethik in der Medizin, a patient's refusal to undergo treatment is summarized in his quote: "So much has happened with syringes-my mother died of it and three acquaintances as well." (NN, 2002) The syringes are condensed signs, which suggest his fears, his negative experiences, his family history and his seemingly superstitious associations. In fact, the symbol of the syringes crystalizes at least four other stories that are interwoven in the patient's reduced story that is conveyed in the case description: the illness and death of his mother as well as three other acquaintances which, in turn, pointedly draws the attention to the diachronic perspective of illness experiences in which this episode is embedded. Considered as symbols, the syringe thus stands for something else and "creates a range of associations, beyond itself" (Hamilton, 2017, p. 93). When the reduced sign is identified and unpacked, a symbol can unfold multiple meanings and stories.

Aphoristic statements represent another, seemingly reduced form in case studies. In the above mentioned case study, the patient is quoted with the following words: "When it hits you, it hits you!" (NN, 2002). Aphorisms, as Levine and Bleakley argue, can be "pearls of wisdom, polished through loving repetition" (Levine and Bleakley, 2012, p. 154). They can play an important role in medicine as heuristics or rules of thumb for practice (Levine and Bleakley, 2012, p. 153), being an aide-memoire, an aid in clinical judgment, professional behavior and professional identity construction. In this sense, the aphorism quoted from the patient is a condensed heuristic that illustrates his fatalistic disposition. It is a concise rule of thumb that the patient shaped over time from his observations and conclusions about the powerlessness of the individual in the face of illness. Similar to the syringe, the aphorism enables the patient to communicate how he relates to his body and illness. The patient's simplistic, reduced statement reveals the patient's ties to life and death and indicates his sense of resignation, passivity, and stoicism.

Despite the interpretations we have offered here, it should be clear that a case represents an open form that invites multiple readings and uses. Therefore, the symbol of the syringes and the aphoristic statement, for example, may or may not be taken up and interpreted by the reader or the commentator. When they are not taken up explicitly, the reduced forms invite processes of recognition and categorization, which are useful tools in the diagnostic training of professionals. When they are taken up and consciously considered, readers can approach them from different angles and reassemble them in a new story. Processes of reduction and reduced forms thus express multiple invitations. The invitation to interpret, unfold and unpack is often accepted by the commentators of a case, whose responses to the dilemma and whose answers to the implicit or explicit question the case raises are described in the commentaries that follow a case. Like our interpretations of the functions and meanings of direct speech, symbols and aphorisms, the commentators select phrases or other types of information, which they find puzzling and they speculate on the possible meanings. In Ethik in der Medizin, quantitatively and qualitatively reduced case descriptions typically entail several pages of commentaries, which are the commentators' individual interpretations and retranslations of the presented case. By means of their reduced form and the ties they generate, cases are thus remarkably productive.

\section{Conclusion}

In our analysis, we illustrate "reduction at work" in two seemingly different genres and writing practices: illness blogs and case studies. Before we summarize the main insights of our analyses, we want to comment on two aspects that throw something into relief that we have not explicitly addressed in our theoretical reflections nor in the subsequent analyses of our cases: On the one hand, we enacted a form of translational work ourselves by providing English translations of our originally German examples. While we hope that our translations do justice to the German texts, we may have reduced (or falsified) some of the information in the original. Moreover, there is a second layer of translation in which we engaged: in selecting a handful of short quotations from much longer texts, we suggested in our analysis that these excerpts are not reductive but contain thick information. The excerpts may indeed not adequately reflect the entirety of the original text or situation, but they allow us to generate new insights with regard to knowledge translation. One of these insights relates to the strategies of reduction that are common in the work of writers and ordinary people alike: a laconic tone, symbols, personification, aphoristic statements, etc. are forms of reduction that bear some similarities with the esthetics of scientific data and the formalized, condensed styles of medical communication. From this perspective, the binary construction of clinical sources on the one hand and a patient's lived experience on the other hand is difficult to uphold.

By focusing on the ways that reduction functions in translational processes as well as the numerous ties that reduction makes possible, we propose that translation is a powerful transformative tool. In our examples, the writing practices that use reduction do not produce a minor, colorless version of the original. Translations are thus not defined by loss or lack, by betrayal or distortion. Rather, reduction understood as a process of crystallization and thickness brings to light the particular ties that link source and target: the desire for the closest possible approximation of original and target; the attempt to appropriate medical information via style, humor and personification; the desire to familiarize and integrate such information into one's lived experience; the prompt to recognize quickly and intuitively the salient information about a case; as well as the invitation to unpack and reassemble the condensed, crystallized pieces of information that add specificity to an anonymous, generalized case description. In our examples, the ties between source and target are characterized by positive attitudes, motivation and effects: the clinical ethicist's curiosity about the complexity of an ethical case is satisfied; the doctor's competence of quick recognition and identification is rewarded and a sense of community and shared experience is created; a writer's anxiety of the unfamiliar is appeased and his sense of powerlessness is mitigated by his appropriation of the medical jargon and an ensuing sense of empowerment and increase in knowledge. These ties are, to some extent, simplified descriptions. After all, the ties that attach us to texts, cases and medical problems tend to be much more varied and complex. Moreover, the ties that we have found in our examples with doctors on the one side and patients on the other side do not exclusively belong to either group. For example, the author of a case study also appropriates information by selecting which information is relevant or irrelevant. Vice versa, a sense of community and recognition is fostered by blogs, which reach out 
to an anonymous readership who may respond via commentaries and a sharing of related, personal anecdotes. In identifying and describing some of the ties that are built in contexts of translation, this paper provides a more capacious and more positive account of the gains of reduction in translational practices.

\section{Data availability}

The datasets we use in this contribution comprise a publicly accessible blog (https://www.wolfgang-herrndorf.de), as well as articles published in the German academic journal Ethik in der Medizin.

Received: 12 November 2019; Accepted: 22 April 2020;

Published online: 03 June 2020

\section{References}

Abrams MH, Harpham GG (2012) A glossary of literary terms, 10th edn. Wadsworth, Boston

Ahn AC, Tewari M, Poon C, Philipps RS (2006) The limits of reductionism in medicine: could systems biology offer an alternative? PLoS Med 3:709-713. https://doi.org/10.1371/journal.pmed.0030208

Baker M (ed) (2001) Routledge encyclopedia of translation studies. Routledge, New York, NY

Banerjee M (2019) Towards a science of the self: autism, autobiography, and animal behavior in temple grandin's Animals in Translation. Zeitschrift für Anglistik und Amerikanistik 67.1:53-72

Behrens R, Zelle C (eds) (2012) Der ärztliche Fallbericht. Epistemische Grundlagen und textuelle Strukturen dargestellter Beobachtung. Harrassowitz Verlag, Wiesbaden

Campo R, Doty M (2018) Teaching physicians not to be afraid of poetry. JAMA 320(15):1520-1521

Cartwright N (2007) Are RCTs the gold standard? BioSocieties 2:11-20. https://doi. org/10.1017/S1745855207005029

Cartwright N (2011) A philosopher's view of the long road from RCTs to effectiveness. Lancet 377/9775:P1400-1401. https://doi.org/10.1016/S0140-6736 (11)60563-1

Chambers T (1999) The fiction of bioethics. cases as literary texts. Routledge, New York, NY, London

Damrosch D (2003) What is world literature? Princeton University Press, Princeton, NJ

Düwell S, Pethes N (2014) Fall-Fallgeschichte-Fallstudie: theorie und geschichte einer wissensform. Campus Verlag, Frankfurt/Main, New York, NY

Engebretsen E, Sandset TJ, Ødemark J (2017) Expanding the knowledge translation metaphor. Health Res Policy Syst 15(1):19. https://doi.org/10.1186/s12961017-0184-x

Felski R (2016) Comparison and translation: a perspective from actor-network theory. Comp Lit Stud 53(4):747-765

Friedman SS (2011) Why not compare? PMLA 126(3):753-762

Ford PJM, Dudzinski DM (2008) Complex ethics consultations: cases that haunt us. Cambridge University Press, Cambridge

Forrester J (1996) If $\mathrm{p}$, then what? Thinking in cases. History of the human. Sciences 9(3):1-25. https://doi.org/10.1177/095269519600900301

Hamilton S (2017) Essential literary terms: a brief norton guide with exercises. W. W. Norton \& Company, New York, NY, London

Hemingway E (1999) Death in the afternoon. Scribner, New York, NY

Herrndorf W (2013) Arbeit und Struktur. Rowohlt, Berlin

Hess V (2007) Observation und Casus: Status und Funktion der medizinischen Fallgeschichte. In: Süßmann J, Scholz S, Engel G (eds) Fallstudien: Theorie-Geschichte-Methoden. trafo Verlag, Berlin, pp. 34-59

Höttges B (2009) Blogging the pain: grief in the time of the internet. gender forum: an internet J Gender Stud. Special issue: literature and medicine II. 26. http:// genderforum.org/literature-and-medicine-ii-issue-26-2009

Hunter KM (1991) Doctors' stories. The narrative structure of medical knowledge. Princeton University Press, Princeton

Jolle A (1968) Einfache formen, 4th edn. Max Niemeyer Verlag, Tübingen

Jonsen AR, Toulmin S (1989) The abuse of casuistry. A history of moral reasoning. University of California Press, Berkeley, Los Angeles, London

Kaiser MI (2011) The limits of reductionism in the life science. Hist Philos Life Sci 33(4):453-376

Kaiser MI (2015) Reductive explanation in the biological science. Springer International Publishing, Cham

Kitzmann A (2003) That different place: Documenting the self within online environments. Biography 26:48-65
Kudlich H (2007) Der Fall in der Jurisprudenz-Zwischen Einzelfallentscheidung und systembildendem Baustein: SchulFÄLLE, EinzelFALLentscheidung und FALLweise Fortentwicklung des Rechts. In: Süßmann J, Scholz S, Engel G (eds.) Fallstudien: Theorie-Geschichte-Methoden. trafo Verlag, Berlin, pp. 82-99

Levenstein S (2009) Against reductionism. BMJ 339:b3855. https://doi.org/10.1136/ bmj.b3855

Levine D, Bleakley A (2012) Maximising medicine through aphorisms. Med Educ 46(2):153-62. https://doi.org/10.1111/j.1365-2923.2011.04141.x

Luhmann N (1987) Soziale systeme. grundriss einer allgemeinen theorie. Suhrkamp Verlag, Frankfurt/Main

Mittell J (2004) Genre and television: from cop shows to cartoons in American culture. Routledge, New York, NY

Nagel E (1961) The structure of science: problems in the logic of scientific explanation. Hackett Publishing Co, Inc, New York, NY

NN (2002) Zur Frage ethischer Pflichten des Hausarztes bei Behandlungsverweigerung. Ethik Der Med (2002) 14:96

Oró-Piqueras M, Wohlmann A (2015) Serializing age: aging and old age in tv series. Transcript, Bielefeld

Pearce W, Raman S, Turner A (2015) Randomised trials in context: practical problems and social aspects of evidence-based medicine and policy. Trials 16:394-400. https://doi.org/10.1186/s13063-015-0917-5

Ricoeur P (2006) On Translation. Transl. by Eileen Brennan. Routledge, London, New York, NY

Smith S, Watson J (2001) Reading autobiography: a guide for interpreting life narratives. University of Minnesota Press, Minneapolis

Sorapure M (2003) Screening moments, scrolling lives: diary writing on the web. Biography 26:1-23

Süßmann J, Scholz S, Engel G (eds.) (2007) Fallstudien: Theorie-GeschichteMethoden. trafo Verlag, Berlin

Vergnaud L (2018) Translation, in sickness and in health. The Paris Review. https://www.theparisreview.org/blog/2018/08/10/translation-in-sickness-andin-health/

Zaner RM (1993) Troubled voices. stories of ethics \& illness. Pilgrim Press, Cleveland/Ohio

Zaner RM (2004) Conversations on the edge. Narratives of ethics and illness. Georgetown University Press, Washington D.C.

\section{Acknowledgements}

This article was presented in an earlier form at two conferences: (1) "Cultural Crossings of Care-An Appeal to the Medical Humanities" in Oslo, Norway (26-27 October 2018) and (2) "Bodies of Data: Intersecting Medical and Digital Humanities" in Dublin, Ireland (22-23 November 2018). The research for the article was supported by the German Research Foundation (grant no. WO 2139/2-1) and the Danish National Research Foundation (grant no. DNRF127).

\section{Competing interests}

The authors declare no competing interests.

\section{Additional information}

Correspondence and requests for materials should be addressed to A.W.

Reprints and permission information is available at http://www.nature.com/reprints

Publisher's note Springer Nature remains neutral with regard to jurisdictional claims in published maps and institutional affiliations.

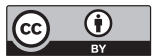

Open Access This article is licensed under a Creative Commons Attribution 4.0 International License, which permits use, sharing, adaptation, distribution and reproduction in any medium or format, as long as you give appropriate credit to the original author(s) and the source, provide a link to the Creative Commons license, and indicate if changes were made. The images or other third party material in this article are included in the article's Creative Commons license, unless indicated otherwise in a credit line to the material. If material is not included in the article's Creative Commons license and your intended use is not permitted by statutory regulation or exceeds the permitted use, you will need to obtain permission directly from the copyright holder. To view a copy of this license, visit http://creativecommons.org/ licenses/by/4.0/.

(C) The Author(s) 2020 